\title{
MONOARTHRITIS BY AMERICAN TEGUMENTARY LEISHMANIASIS: CASE REPORT
}

Priscila Dourado Evangelista ${ }^{1, \star}$, Thalita do Nascimento Silva ${ }^{1}$, Lucas Pinho Alves ${ }^{2}$, Ingrid Almeida Moura Martins ${ }^{2}$, Ana Victória Albuquerque Araújo²

1.Hospital Geral Dr. César Cals, Fortaleza (CE), Brazil; 2.Universidade de Fortaleza, Fortaleza (CE), Brazil.

*Corresponding author: prisdourado@yahoo.com.br

\section{BACKGROUND}

Leishmaniasis is an infectious, noncontagious disease caused by Protozoa of the genus Leishmania, which are incolled in humans through the bite of phlebotomine sandflies. These parasites proliferate in reticuloendothelial cells of the affected individuals. In rare circumstances, one of the observed symptoms is joint pain. In the scientific literature there are records of Leishmania donovani found in histiocytes of the joints. American tegumentary leishmaniasis (ATL) is one of the leishmaniasis forms. Immunosuppression caused by cancer, chemotherapy, transplantation, or untreated HIV infection may predispose to rare opportunistic infections, such as leishmaniasis of the joints. In these patients, ATL may present peculiar characteristics, such as dissemination of parasites, atypical presentation, which are often severe, and even visceralization.

\section{CASE REPORT}

Female, 75 years old, cardiopathic, presented edema, flushing and soft tissue heat in the third right finger, 2 days ago, associated with joint limitation. She denied local trauma or recent infections. She started using cephalexin for 7 days, with worsening of edema and local hyperemia. She started treatment with ceftriaxone; however, she presented worsening of the lesion after $48 \mathrm{~h}$, with emergence of local pus, ulcer with raised lips and arthritis in the third right proximal interphalanana. A biopsy of the lesion was performed evidencing the edge and bed of cutaneous ulcerated lesion with pseudoepitheliomatous hyperplasia, suggestive of ATL. Patient initiated the use of liposomal amphotericin B at a dose of $3 \mathrm{mg} / \mathrm{kg} /$ day for 7 days, with a cumulative dose of 1,050 mg. After the end of treatment, the patient was monitored monthly where there was progressive improvement of the lesion, and at the end of 120 days the lesion was fully healed (Figure 1a-d). Patient was monitored every 2 months for 12 months.

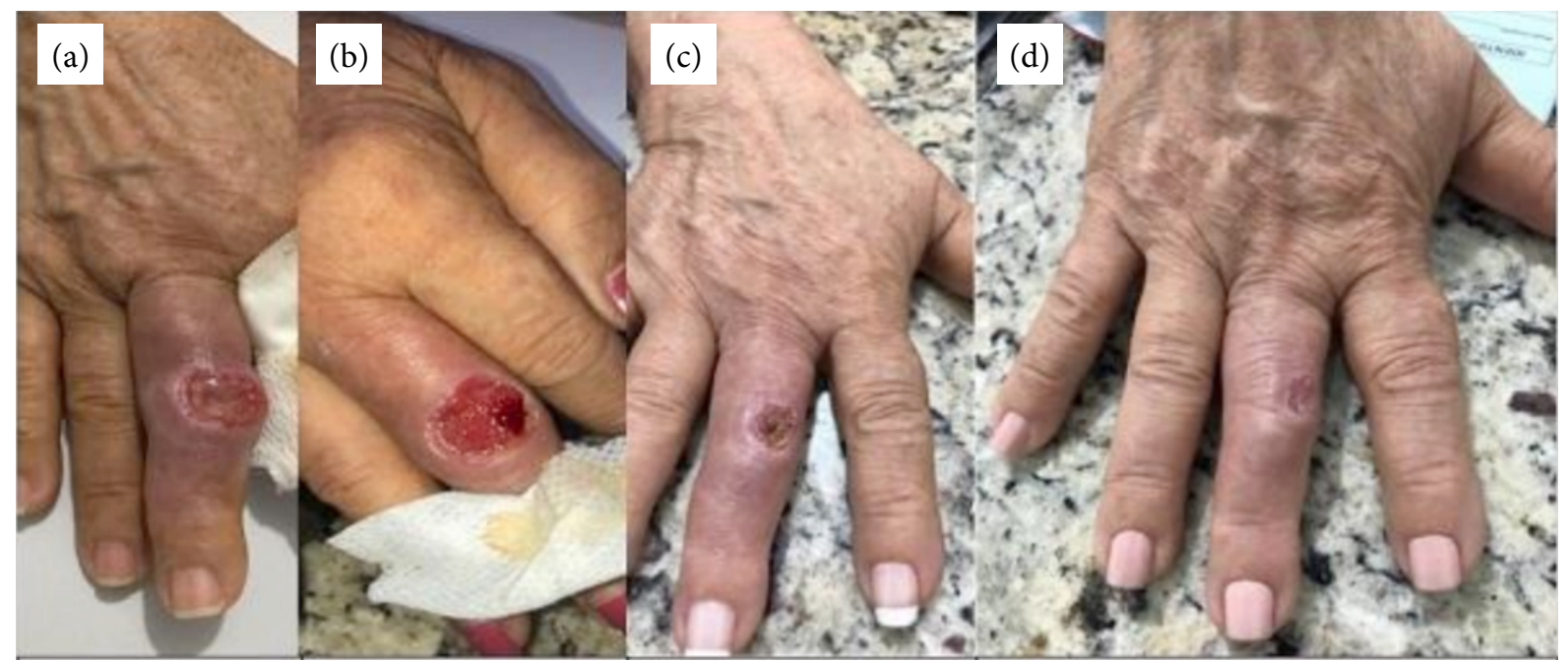

Figure 1. American tegumentary leishmaniasis and infectious arthritis. Evolution after treatment with liposomal amphotericin B at a dose of $3 \mathrm{mg} / \mathrm{kg} /$ day for 7 days. 


\section{CONCLUSION}

Meglumine antimoniate is the first choice of treatment. Due to age and cardiopathy and in order to minimize the adverse effects of treatment, it was opted for the use of liposomal amphotericin B, which is a leishmanial drug used in this context in the treatment of ATL based on clinical practice with visceral leishmaniasis. The protozoan was not observed in the biopsy of the skin, but as characteristics of the lesion and the histopathological result were suggestive of the infection by the protozoan Leishmania. In this case, no synovial biopsy was performed. In addition, monitoring progress was important in your treatment condition. Infectious arthritis developed, in this case, probably by contiguity.

\section{KEYWORDS}

Monoarthritis, Leishmaniasis, Meglumine antimoniate. 